health of person exposed,etc. 2. A disinfecting oven for bedding, clothing, and isolation and disinfection."

Mr. T. J. Dyke (Merthyr Tydvil) says : "I. Yes, it is contagious. Given a person sick of this form of fever, the occupants of the house, the attendants on the sick, and persons using a cesspit-closet or inhaling gases from sewer from a frequented water-closet, are liable to take the disease. 2. Isolation of the sick and removal to a fever-hospital. Fumigation with burning sulphur of the dwelling before the removal of any clothing, etc.; then thorough cleansing of house, walls, etc., with water and carbolic acid soap."

Mr. Alfred Haviland (Northampton) writes : " I. Yes, I thoroughly believe that typhoid fever is both infectious and contagious, and I certainly would not allow a child from an infected house to go daily to school from it, nor to a boarding-school, without thorough disinfection of every article of wearing apparel, and not until it had been positively ascertained that the scholars are free from infection, as indicated by the non-appearance of the disease after a maximum number of days of incubation have elapsed. I have had too much experience of the fallacious doctrine held by non-contagionists to hold any other views than those I have expressed. 2. a. The providing of pure water from a source incapable of being polluted by sewage. $b$. Isolation of the cases as far as practicable. . $c$. Thorough disinfection of the excreta. $d$. Thorough disinfection of clothing, and, in the absence of a disinfecting-stove, destruction by fire of the bedding. e. Disinfection of the house by washing, white-liming, and sulphur fumigation. $f$. The closing of all wells suspected of sewage-contamination, and, when the owners of wells are obstinate, the flushing with strong solution of carbolic acid of all the privies and drains surrounding the well. If there be a leakage, it will soon be discovered, the water will be impregnated with carbolic acid, and the obstinate owner will be convinced when his water is no longer drinkable. $g$. Prohibiting children from going to school from infected houses."

So much for medical officers of health. Space will only permit me to quote a few other authorities who have kindly favoured me with replies.

Sir Thomas Watson, Bart., says: "I hold that, like small-pox and the rest, the disorder may be taken by breathing emanations from the sick person's body or bed, and that scrupulous care should be taken in all cases not to inhale the poison in that way."

Dr. Reginald Southey, Physician and Lecturer on State Medicine and Hygiene at St. Bartholomew's Hospital, says : "Facts which have come under my own observation make me believe and teach that enteric fever is a communicable fever, but that its poison-entity is not possessed of high resisting power-in other words, is easily rendered inert matter."

Dr. T. W. Grimshaw (Dublin) says : "Yes, it is contagious. I have seen a case arise by contagion in hospital."

Dr. Alfred Carpenter says : "I am satisfied as to its infectious character. A person shaking hands with a typhoid patient might take the disease, but the contagium must find an entrance."

Dr. Michael W. Taylor writes: "I believe in the dissemination of typhoid by contagion; in fact, I am positive about it. After close contact with the sick by inhalation of the breath or effluvia from skin, by food and drink, especially milk, absorbing the emanations from the surfaces of lungs and skin, or from becoming soiled by the alvine excreta."

Dr. Alexander Collie, Physician to the Homerton Fever Hospital, in his remarks on two cases of enteric fever (published in the BRITISH MEDICAL JourNaL) which occurred in the hospital, states: "That they caught it by personal communication by visiting the sick", and continues as follows: "Without ascertaining that the contagion of enteric fever is as potent as that of typhus or scarlet fever, it is nevertheless very real, and to persons between fifteen and thirty a very great danger. Several of our nurses, nearly all of whom were between twenty and thirty, have contracted the disease while nursing enteric patients."

My own experience corroborates Dr. Collie's, that even experienced and forewarned nurses contract typhoid from their patients; but time will not permit me to quote further evidence on this subject, and I will now conclude with the following observations. There is no proof that the semina of infection reside solely in the intestinal excreta. Typhoid spreads by contagion like other zymotic diseases, being transmitted into the body by inhalation into the lungs; by being swallowed with the drink or food ; or by dust. The poison may not be so volatile as that of scarlet fever, and therefore requires a carrier or vehicle (currents of air are sufficient); and, when the patient is susceptible, it proves a highly contagious poison. The means to be employed to prevent its spread should be promptly and rigidly carried out. They consist of immediate isolation; thorough disinfection of excreta ; procuring pure water; thorough disinfection of clothing by hot air at a temperature of $300 \mathrm{deg}$. or their destruction by fire; preventing children from going to school or other public resorts from an infected house without thorough dismfection, and not until it has been ascertained that the child is free from infection. There is risk in any susceptible person visiting the infected house. As rigid precautions should be employed as in cases of scarlet fever, substituting the disinfection of the discharges on their very issue from the body for the oiling of the skin to prevent the spread of scarlet fever from the surface of the body. The practice of admitting typhoid fever patients into the wards of general hospitals is to be condemned. Nurses should be selected from those who are protected by a previous attack. Knowing how highly contagious a disease typhoid fever is, and knowing, too, how subtle is its poison, I cannot too strongly condemn the practice of "masterly inactivity" pursued by those who still hold an opposite opinion.

\section{ZYMOSIS AND SEPTICAMIA.}

\section{By THOMAS DARBY, F.R.C.S.I., Bray.}

THE terms "zymosis", "septicæmia", and "blood-poison" have of late years come into such general use, and are so loosely and indiscriminately applied by a large majority of the members of the medical profession, that it has become a serious difficulty to those who desire to be accurate to pronounce upon any given case, whether it be of epidemic or accidental origin. The great leaders of physiological and pathological opinion, who no doubt use these terms with greater accuracy and precision, may fairly say: We are not responsible for any misapplication of technical terms on the part of others. But when misapplication becomes general, it would appear that some obscurity or defect must exist ; and, if that be admitted (and it can scarcely be denied) the time has arrived when attempts should be made to clear away the obscurity and remove the defect. The small amount of our knowledge of the true-connection which subsists between life and material organisation, no doubt, gives rise to this obscurity; and it is with a view, if possible, to lessen the obscurity and remove, at least in some slight degree, the defects to which I have alluded, that I ventured, in my opening address to the Dublin Obstetrical Society, in November 1877 , to bring forward the subject. With this same object, I now ask the members of the British Medical Association to bear with me while $I$ in part recapitulate what $I$ then said.

In order to place the matter clearly before us, I would ask the following questions.

I. Does fermentation ever take place or arise in the living blood?

2. Does putrid blood ever circulate in the living body ?

3. Does the term "blood-poisoning" mean that the blood primarily, apart from the living tissues with which it is associated, takes a poison and produces disease by distributing it through the system?

These are questions not of theory, but of fact ; and I ask them because, in the common employment of these terms, it is implied that such phenomena take place. That they are not really facts, I shall endeavour to prove : first, by the consideration of disease produced by inoculation, requiring inflammation for its development; and then, by reference to essential disease, in the development of which inflammation plays no necessary part; in conclusion, stating the doctrine which I myself hold upon the subject.

I. For an example of the first of these, we may take the case of a dissecting wound, where the matter inoculated is putrid, and the inflam. mation which follows is diffusive, irregular, and undefined. Other examples may be seen in the inflammation resulting from the specific virus of syphilis and vaccinia, which is tolerably regular in its course and definite. I would ask : Do these exhibit any sensible evidence, throughout their whole course, that the blood ferments or becomes putrid?

Though not exactly coming under this head, I may here adduce the case of gangrene, where the affected part ferments, evolves gas, and becomes sensibly putrid, while still retained, not only in immediate contact with, but actually continuous with, the surrounding living tissues. Even here the blood in circulation is not sensibly putrid. On the contrary, the gangrenous part is sloughed away, and has evidently no real connection with the living tissues; in fact, it ceases to be a living portion of the body.

II. Of the second class of diseases to which I would refer, namely, those essential diseases in the development of which inflammation pliys no necessary part, I take for examples fever, cholera, and purpura. In these, the blood may be considered as essentially implicated ; and yet, in the course of my observation of them, I have not been able to discover fermentation in the blood analogous to the fermentation and putrefaction which we observe in dead organic fluids. And I would here remark, in reference to deductions drawn from experiments upon these dead fluids, that they cannot be fairly extended to anything taking 
place in the blood as it is in the living body, the fact being that there is no true analogy between the cases, as the experiments ar $\boldsymbol{k}$ conducted under totally different conditions. Even where we follow the diseases to which I have referred under this head to the dissecting-room, the blood presents no sensible difference from that which it does in death from other diseases ; whereas, if those processes were going on, they must become sensible.

In proof of this, I would call particular attention to that awful disease named by Stokes "Acute Purpuric Fever", and aptly compared by Dr. Lyons to the "Black Death" of the middle ages. In this disease, the truth, that "a little leaven leaveneth the whole lump", is painfully exhibited. According to my observation of it, putrefaction of all the tissues sets in with such appalling rapidity that it may be said that the person attacked by it has scarce time to die before his whole body has become sensibly putrid. Yet I believe that, had we the means of ascertaining the fact, the blood would be found the last thing to putrefy, and then not till after death. I have adduced this case, in contrast to the illustration from gangrene, in further proof that, where putrefaction actually does take place, the part is already dead.

III. I come now to state, in conclusion, the doctrine that I hold myself upon the subject.

I hold life in the individual organism to be an unit, one and indivisible, wholly present in every part-recipient, percipient, of every impression, whether it be from within or from without, healthy or morbific. Where disease or injury is inflicted on the living body, its organic life is assailed, and its vital susceptibility recognises, resents, and resists the assailant. Thus, according to my belief, disease is not the consequence of organic changes; but these changes themselves result from a primary injurious impression made upon the life, which in each individual is an indivisible unit, the whole of which is present in every part of the organism. From this primary injurious impression thus made upon the life-unit, result secondarily the various changes in the organic solids and fluids of the body which take place in disease.

According to this view, it is as erroneous to attribute one disease, say, to shocks received by the nervous system, as to attribute another to blood-poisoning; the effects upon the nervous system and the blood being in each case secondary, the shock being primarily sustained by the life-unit, and resulting in the changes whether in the nerves or blood. The nerves and blood must both be alive; dead nerves do not receive impressions any more than dead blood circulates. Thus life is the great antiseptic which prevents or resists death; when it can resist no longer, it departs. The integral changes which take place in the blood in disease are not of the nature of true fermentation or putrefaction. Such changes are, as I contend, vital. They never take place except in the living tissues, while true fermentation and putrefaction can only arise in the dead. Every disease to which flesh is heir results from noxious or morbific influences communicated from without, or generated within the organism, but affecting the life-unit primarily; and, therefore, while it may be quite proper to consider these influences as poisons, yet they ought, as I believe, to be considered as life-poisons, and their action upon the constituents of the organism as altogether secondary.

In accordance with this, instead of attributing the power of producing disease to poison received by the blood, and carried and distributed through the body by a sort of hydraulic action, I ascribe the communication of disease to the affection of the whole vital susceptibility. When, for example, I vaccinate a child, the effect is produced not by the blood distributing the vaccine poison mechanically through the system, but by the impression made upon the life-unit producing those results upon the whole organism, by which is conferred immunity from the infection afterwards.

Similarly, when a man takes a fever, he has not to wait for the disease until the blood has carried it to each part of his frame; but the whole man, by a simultaneous shock, has received it through the affection of vital susceptibility.

The conclusion at which I arrive is that the terms zymosis and septicæmia, applied to disease, imply that which is not the fact, and lead to erroneous practice on the false supposition that there is a condition of fermentation or putridity in blood in circulation; and I would maintain that where disease or injury is inflicted upon the body, the organic life is assailed, and the susceptible life-unit recognises, resents, and resists the assailant. The questions with which I began these remarks are fundamental to this discussion, and must and will be answered. I have endeavoured to deal with them here, not from a speculative, but from a clinical standpoint, on the ground of experience and observation by the sick bed.

And it is in the twofold hope that an incorrect use of terms may be checked, and that the truth, whatever it is, may be discovered by observation and discussion, that I have ventured to press this matter upon attention.

\section{NOTES ON SEWER-GAS POISONING.}

\author{
By J. BROWN, L.R.C.P.Lond., etc.,
}

\author{
Medical Officer of Health to the Bacup Local Board.
}

IN the JouRNal for November 16th there was an interesting paper, by Mr. Trend, on sewer-gas poisoning. During the past few months, I have made a number of observations on the same subject, as they confirm his opinion, and also give other effects of sewer-gas poisoning. I have notes of thirteen houses, in which there were grave sanitary defects. In seven houses, the slop-stone pipe was untrapped, and went straight into the drain, and from which there arose bad smells, especially in the hot weather. In the remaining six, there were untrapped and rubble drains, which were close to the door of the house, or passed beneath the floor.

I. Submaxillary abscess, and enlarged cervical glands, in children aged two and five years respeetively. There were untrapped slop-stone, and bad smells from a rubble drain.-2. Cervical abscess in a child, aged nine years, probably due to bad smell from defective drain.-3. Axillary abscess and "summer-diarrhoea". The child, aged five years, also had other enlarged glands in the axilla and elbow. Diarrhœa occurred in a patient aged six weeks. Another child had recovered from a submaxillary abscess. There were bad smells from untrapped slop-stone and defective drains. -4. Two cases of inguinal abscess and summer-diarrhae. One of twins died from exhaustion, due to inguinal abscess, and the other from diarrhœa. The mother recovered from inguinal abscess, the cause being an untrapped slop-stone pipe. 5. Facial abscess in a girl, aged nine years. This was probably due to sewer-gas from an untrapped slop-stone pipe.-6. Pelvic abscess, and three cases of "summer-diarrhoea". A patient had been confined six weeks. She was very anæmic, and had no appetite. This was due, undoubtedly, to the bad smell in the house. She was taken ill with an abscess in the pelvis. Just at the same time there were three other cases of summer-diarrhoea in the house. The infant died. For the sake of the woman, I recommended that the family should remove at once, which they did, and the patient made a good recovery. The abscess discharged itself per vaginam. The cause was a defective privy, from which there was a continual leakage of fæcal matter into the house.-7. Multiple abscesses. A baby, aged six months, had twenty abscesses, scattered on its legs, arms, and body. This state was due to bad emanations from a defective privy. The privy was at once altered at my suggestion, and the lpatient speedily recovered.-8. Temporal abscess in a patient aged eleven years. The cause was foul emanation from a defective drain. - 9. Typhoid Fever. A death from typhoid fever being reported to me, I inspected the house, and found that bad smells came from the untrapped slop-stone pipe.-10. Typhoid Fever. Another death from typhoid fever was reported. On inspection, I found the slop-stone untrapped, and an untrapped drain close to the door.-II. Typhoid Fever. This was a case of typhoid fever in a gentleman living in a new, well-built house. On inspection, I found the drains and slopstone trapped. The wife, however, complained of bad smells coming from the water-closet, which was on the first floor. The water-supply in the summer being limited, the drain would not be well flushed. The mephitic gases, generated in large quantities in hot weather, would soon saturate the water in the pan of the water-closet, and pass into the house. The drain was long and unventilated ; and the sewer-gases, being of lighter specific gravity than the air, would seek an outlet at. the highest elevation, which would be the water-closets. The drain has since been ventilated. The patient died.-12. Diphtheria, and three cases of Sore throat. A child, aged three years, had diphtheria, and died in three days. In the same house, there were three adults suffering from sore throats, all of whom recovered. I found that there was a bad smell from untrapped slop-stone.-13. Puerperal Septicamia. The third day after confinement, the patient had usual symptoms of septicæmia. She nearly succumbed two or three times. After about five weeks, she had a relapse, which proved fatal. In this case there was a foul smell from an untrapped drain, within a few feet of the door where the patient was confined.

REMARKS. - It is difficult to state definitely the cause of many diseases. In some of the cases given above, it may be a coincidence, and sewer-gas may not have been the cause. Though $I$ think in most, if not in all, sewer-gas was the chief factor, I would not say positively typhoid fever can be generated de novo from sewer-gas; yet my experience goes to prove that much may be said in favour of it.

Summer-diarrhoa, especially in infants and young children, I believe, is often due to sewer-gas. In the summer, decomposition of sewage is very rapid. Infants who are nearly all day indoors in houses in which sewer-gas exists (and there are, unfortunately, a large number among the poor) soon get diarrhœe. Of course, there are other things to produce it. 